Article

\title{
Rendering Mortars with Low Sand and Cement Content. Incorporation of Sanitary Ware Waste and Forest Biomass Ashes
}

\author{
Catarina Brazão Farinha ${ }^{1,2} \mathbb{D}$, Jorge de Brito ${ }^{1, *(\mathbb{D})}$ and Rosário Veiga ${ }^{2}(\mathbb{D}$ \\ 1 CERIS, Instituto Superior Técnico, University of Lisbon, Av. Rovisco Pais, 1049-00 Lisbon, Portugal; \\ catarina.brazao.farinha@ist.utl.pt \\ 2 National Laboratory for Civil Engineering, Av. do Brasil 101, 1700-066 Lisbon, Portugal; rveiga@lnec.pt \\ * Correspondence: jb@civil.ist.utl.pt; Tel.: +351-218418118
}

Received: 1 April 2020; Accepted: 27 April 2020; Published: 30 April 2020

\begin{abstract}
The incorporation of wastes in new materials and products is an emerging trend, reducing virgin materials' consumption and landfill deposition and the associated environmental impacts. Cement-based mortars can encapsulate some wastes, with the benefits stated above. In three previous researches, it was found that forest biomass bottom ashes (up to $15 \%$ by volume of cement), powder of sanitary ware (up to $20 \%$ by volume of sand) and sanitary ware particles above $2 \mathrm{~mm}(100 \%$ by volume of sand) can be incorporated in rendering mortars, replacing cement or sand. Several tests were performed, and it was found that each waste's incorporation presents advantages and limitations, when compared with a reference mortar. In this research, the aim was to take advantage of the best features of each waste, combining them in order to optimize the new mortars' characteristics. Therefore, mortars with one, two and three wastes were analysed in this research. The ternary mix mortar had a volume of wastes equal to $83 \%$, resulting in a mortar with $15 \%$ less cement (by volume) and without any natural aggregate (all replaced with the sanitary ware wastes). The fresh, water and mechanical behaviour of the mortars with and without wastes are presented in this research. It was concluded that it is possible to take advantage of the best features of each waste and achieve mortars simultaneously with high volume of wastes and a better performance than the reference mortar (without wastes).
\end{abstract}

Keywords: sustainability; eco-mortar; render; waste; industrial waste; re-use; recycle

\section{Introduction}

In 2016, the total weight of wastes generated by the EU-28 amounted to 2538 million tonnes [1]. Construction and demolition waste represented $36 \%$ of the total wastes generated [1] and was still the most pollutant sector. It was also responsible for producing materials that have great impacts on the environment, such as cement. According to the European Cement Association, one tonne of CEM II produced releases $738 \mathrm{~kg}$ of $\mathrm{CO}_{2}$ into the atmosphere [2].

According to the European Commission [3], the long-term goal of Europe is to become a recycling society, avoiding waste production and using wastes (the ones that are unavoidable) as raw materials whenever possible, thus minimizing the extraction of additional natural resources. In order to achieve the aims proposed, Directive 2008/98/CE of the EU set up a minimum rate of reuse, recycling or other material recovery [4], 70\% (by weight) for construction and demolition waste.

The encapsulation of wastes in hydraulic materials, such as cement-based mortars, is a possible solution for the wastes' management [5-21].

The incorporation of wastes, replacing the original constituents of the mortars (natural aggregate or cement), can improve some characteristics of the mortars, and consequently improve their technical 
performance. The authors of this research, as well as others [6,14-20,22-26], have been studying the incorporation of wastes in cement-based mortars, namely render mortars and found that the incorporation of wastes is responsible for modifying some properties of the mortars, improving some properties and compromising others.

In three previous researches $[5,6,14]$ from the authors of this research, the incorporation of three wastes in rendering mortars was analysed: forest biomass ashes, sanitary ware waste powder and sanitary ware waste fine aggregates. The main advantages and limitations of each waste are summed up next.

The incorporation of forest biomass bottom ashes (FBA) in mortars significantly improves the environmental benefits of the mortars [27], since it reduces the volume of cement content. The encapsulation of biomass ashes in cement-based mortars also reduces the environmental impacts of landfill, since the cement matrix is responsible for a reduction of release of elements such as arsenic (As), chromium ( $\mathrm{Cr}$ ) and molybdenum (Mo), when compared with the release of pure biomass ashes [28]. In a previous research, it was found that the replacement of CEM II/B-L $32.5 \mathrm{~N}$ at 15\% (by volume) with forest biomass bottom ashes resulted in mortars with lower $\mathrm{CO}_{2}$ emissions, by about $13 \%$, when compared with a reference mortar [27]. Technically, it was found that the replacement of cement with FBA produced weaker and slightly more water-absorbent mortars, but also more deformable and ductile [14], which are considered advantages in rendering mortars. A decrease of mechanical strength was also found by other researchers $[29,30]$.

In another research [6], it was found by the authors that the incorporation of sanitary ware powder (SWP) waste in rendering mortars resulted in stronger and less permeable mortars, which agrees with the findings of other researchers [31]. The mortars presented high flexural and compressive strengths [6,31]. The increments of strength at 28 days were $250 \%$ and $227 \%$, respectively, for flexural and compressive strength [6], relative to the reference (REF) mortar. The water permeability (by capillarity) was reduced in the first minutes by $30 \%$, relative to the EF [6]. However, the incorporation of this type of waste (as powder) was noticed to be detrimental to the mortars' deformability, which led to higher susceptibility to micro-cracking [6]. This was responsible for a reduction of strength over time. At 90 days, the flexural strength was reduced by about $48 \%$ and the compressive strength by about $36 \%$ [6]. In render applications, susceptibility to cracking is a huge disadvantage because it is responsible for a degradation of the aesthetical global appearance of the surfaces [32], an increment of water permeability and potentially the appearance of other anomalies such as bio-colonization.

On the other hand, it was also noticed in other research [5] that sanitary ware fines (SWF) waste can be incorporated in mortars, replacing with equal size particles natural aggregate at $100 \%$, and present a good technical performance [5]. The angular shape of SW resulted in stronger mortars, with higher flexural strengths. Other researchers also found higher compressive strengths [33,34]. The increment of this strength at 90 days was almost $30 \%$, relative to a reference mortar [5]. The modulus of elasticity was reduced by the incorporation of the waste (by $28 \%$, at 90 days), which indicates better deformability, relative to a reference mortar [5]. The main disadvantage of the incorporation of this waste was an increase of water absorption. The use of SWF waste instead of natural aggregate also resulted in more permeable mortars [5].

Thus, the incorporation of FBA, SWP or SWF in rendering mortars presents some advantages and limitations, relative to a reference mortar. In previous researches, these trends were identified [5,6,14]. In order to fine-tune the global performance of the mortars for current use, the authors combined these wastes in mortars in order to take advantage of the best features of each one, maximising the advantages and limiting the disadvantages, simultaneously increasing the global volume of wastes incorporated. The benefits of high volume of wastes incorporated in terms of environmental impacts, were evaluated in a previous research [27] by a life cycle assessment (cradle-to-gate). It was noticed that the combination of FBA, SWP and SWF resulted in a mortar with less impact in terms of global warming potential, abiotic depletion potential, acidification potential and eutrophication potential. The reduction of $\mathrm{CO}_{2}$ emissions was $14 \%$, when compared with the reference mortar. 
In this research, the wastes were combined first two-by-two and then all together. The combination of the three wastes represented a volume of wastes of $83 \%$.

\section{Materials, Methodology and Methods}

\subsection{Materials}

Silica sand was used as natural aggregate and Portland cement CEM II/B-L 32.5 N (from Secil manufacturer, Portugal) was used as a binder. Three wastes were also incorporated in the mortars: sanitary ware powder (SWP), sanitary ware fines (SWF) and forest biomass ashes (FBA). SWP replaced sand at $20 \%$, SWF replaced sand at $100 \%$ and FBA replaced CEM II at $15 \%$, all by volume.

The sanitary ware was provided by a Portuguese producer of sanitary ware pieces. These ceramics include toilets, washbasins and bidet pieces. The sanitary ware waste was provided in sizes up to $10 \mathrm{~cm}$. Therefore, the waste had to go through a treatment process before its application in mortars. The wastes were crushed in a jaw crusher and a roll mill to reduce their size. Only particles lower than $149 \mu \mathrm{m}$ were used as powder waste (SWP). The SWF particles were lower than $2 \mathrm{~mm}$.

The forest biomass bottom ashes were provided by a Portuguese power generation station that produces energy by burning forest residues. The wastes already came as ashes and did not go through a treatment process before their application in mortars.

Seven mortars were analysed in this research: a reference mortar (without wastes), three mortars with one waste only (SWP, SWF or FBA waste), two mortars with a combination of two wastes, SWF+FBA ( $83 \%$ of wastes incorporated) and SWP+FBA (19\% of wastes incorporated) and a mortar with all wastes SWF+SWP+FBA ( $83 \%$ of wastes incorporated). All mortars had a volumetric ratio of binder to aggregates of 1:4.

\subsection{Methodology and Methods}

The technical performance of the mortars was analysed through their fresh, water and mechanical behaviour.

The fresh behaviour of the mortars was analysed according to their workability and bulk density. Workability is one of the most important fresh-state characteristics of rendering mortars. Without a proper workability, mortars cannot be applied on a vertical façade, covering the irregularities of the substrate. Workability was measured by the consistency through the flow table test performed according to the European Standard EN 1015-3 [35], for which three samples per mortar were tested. The consistency was maintained at $165 \pm 11 \mathrm{~mm}$ for all mortars, guaranteeing they all had a similar workability. The water/binder $(\mathrm{w} / \mathrm{b})$ ratio was made to depend on the consistency table value. The bulk density was evaluated according to the French Standard Cahier 2669-4 [36], for which three samples per mortar were tested.

The water behaviour of the mortars was evaluated through their capillarity-water absorption and drying curves. The velocity of water absorption and the volume of absorbed water are indicative of the water behaviour of the mortars. The water absorption by capillarity test was performed according to the European Standard EN 1015-18 [37]. After absorbing a given volume of water, a mortar should be able to release it whenever the climate conditions allow. Thus, in order to complement knowledge on the water behaviour of the mortars, their drying curves were also analysed in this research. The drying test was performed according to the European Standard EN 16322 [38]. In both tests, three samples per mortar were used.

The mechanical behaviour of the mortars was analysed through their deformability and flexural and compressive strengths. Rendering mortars in general are more often subjected to tensile stresses, namely due to thermal or humidity variations, movements of the substrate or the formation of ice and salts crystallization in their pores. Tensile strength was evaluated through the flexural strength test, performed according to the European Standard 1015-11 [39]. Compressive strength gives an overall idea about the mechanical strength of the renders and, in this sense, was also evaluated. Compressive 
strength was evaluated according to the European Standard 1015-11 [39]. In the flexural strength test, three prismatic specimens per mortar were used except for the FBA mortar for which six prismatic specimens were used and, in the compressive strength test, six (or twelve in the case of the FBA mortars) semi-prismatic specimens, resulting from the previous ones, were tested. The deformability of the mortars was analysed through the modulus of elasticity by frequency of resonance test, performed according to the European Standard 14146 [40]. Three samples per mortar were analysed.

\section{Results and Discussion}

\subsection{Fresh Behaviour}

It was noticed that the incorporation of sanitary ware waste as a filler improved the workability of the resulting mortar (SWP mortar), allowing a decrease of the w/b ratio from 1.3 to 0.9 for similar consistency, when compared with the REF mortar (Table 1). The SWP waste filled the voids between the particles of sand, thus decreasing the water needs of the mortars [6]. On the contrary, the SWF and FBA wastes were responsible for a slight reduction of the mortars' workability. These mortars presented a $\mathrm{w} / \mathrm{b}$ ratio of 1.4, which corresponded to an increase of $8 \%$ in comparison with REF's [5] [14]. In relation to the SWF mortar, the increment of water needs was related to their angular shape. This shape is responsible for an increase of specific surface area, in comparison with the more spherical particles of sand and, consequently, for a higher volume of water needed to lubricate the particles.

Table 1. Fresh state tests results.

\begin{tabular}{|c|c|c|c|c|c|c|c|}
\hline & \multicolumn{7}{|l|}{ MORTARS } \\
\hline & REF & SWF & SWP & FBA & SWF +FBA & SWP+FBA & SWF+SWP+FBA \\
\hline Consistency (mm) & $161.2 \pm 1.8$ & $174.5 \pm 6.4$ & $175.5 \pm 0.7$ & $167.2 \pm 3.1$ & $158.2 \pm 2.3$ & $161.3 \pm 0.8$ & $169.2 \pm 0.8$ \\
\hline $\mathrm{W} / \mathrm{b}$ ratio & 1.3 & 1.4 & 0.9 & 1.4 & 1.5 & 1.1 & 1.2 \\
\hline Bulk density $\left(\mathrm{kg} / \mathrm{m}^{3}\right)$ & $1975 \pm 7$ & $1780 \pm 25$ & $2064 \pm 9$ & $2045 \pm 17$ & $1794 \pm 8$ & $2042 \pm 4$ & $1886 \pm 8$ \\
\hline Reference & - & [5] & [6] & [14] & - & - & - \\
\hline
\end{tabular}

When SWF and FBA were combined in a single mortar (SWF+FBA), the negative effects of both wastes on workability were combined, resulting in a w/b ratio of 1.5 , which was higher than REF's by $15 \%$. When SWP was combined with FBA in the SWP+FBA mortar, a reduction of $\mathrm{w} / \mathrm{b}$ ratio was possible (meaning an improvement of workability), in comparison with the REF mortar. Similarly, when SWP was combined with SWF and FBA in the SWF+SWP+FBA mortar, the negative effects of SWF and FBA on workability were offset by the benefits of SWP and the SWF+SWP+FBA mortar presented a better workability than that of the REF mortar. The mortar presented a w/b ratio $8 \%$ lower than that of the REF mortar, for similar consistency.

In conclusion, SWP+FBA and SWF+SWP+FBA mortars presented improvements in workability, which was due to the SWP waste, i.e., the filler was able to compensate for the negative effects of SWF or FBA on this fresh-state property.

Concerning bulk density, the incorporation of sanitary ware as an aggregate (SWF) or as a filler (SWP) led to a completely different behaviour. Filler incorporation, due to a filler effect, increased the bulk density of the mortars. Aggregate incorporation, on the other hand, was responsible for a reduction of bulk density. The FBA waste also increased the bulk density of the mortars. The combination of these wastes in a single mortar $(\mathrm{SWF}+\mathrm{SWP}+\mathrm{FBA})$ resulted in a lower bulk density, $5 \%$ lower than REF's. The value obtained was an intermediate value between the ones presented by the SWF and SWP mortars. Nevertheless, the differences between bulk densities were noticed to be slight, all the mortars presenting in fact similar values, not compromising this fresh-state characteristic.

\subsection{Water Behaviour}

The water absorption curves of the mortars under analysis at 28 days and 365 days are presented in Figure 1. The initial water absorption rate was analysed through the slope of the first straight line segment of the water absorption curve. This slope corresponds to the capillary coefficient that 
was measured for all mortars and it is presented in Table 2. Of all the mortars presented, the ones that contained SWP waste were the ones with lower slope and therefore lower capillary coefficients (Table 2). On the contrary, the SWF waste was responsible for an increase of this coefficient.
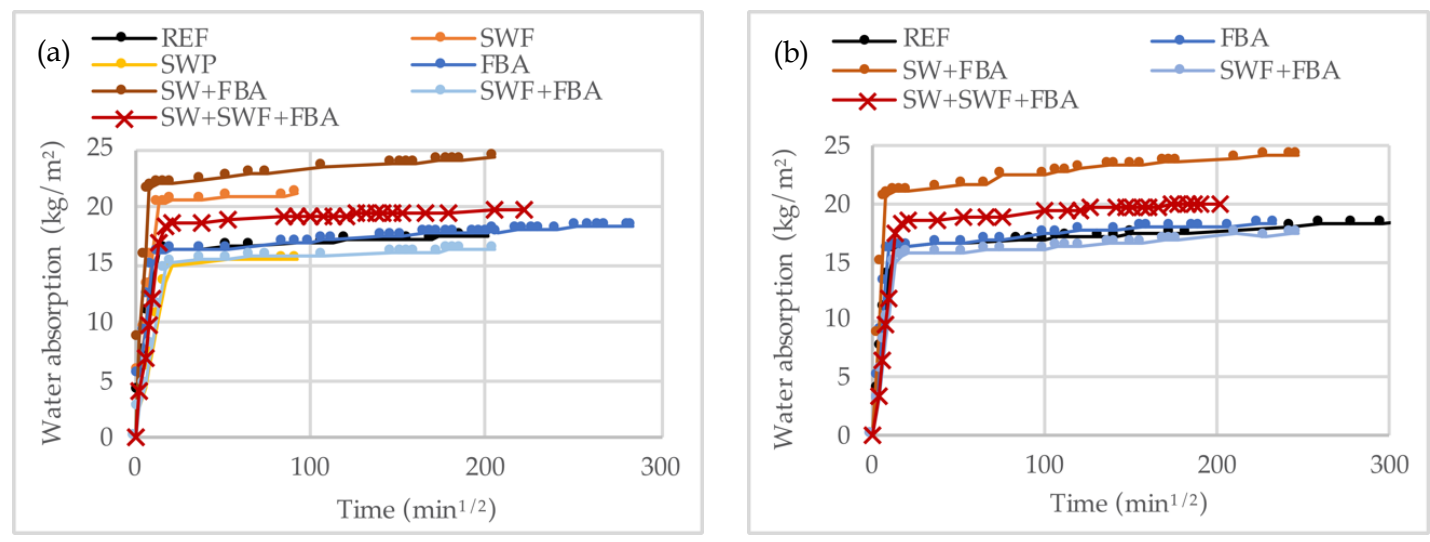

Figure 1. Water absorption curves at 28 days (a) and 365 days (b).

The SWP+FBA mortar presented a capillary coefficient of 0.89 and $1.11 \mathrm{~kg} /\left(\mathrm{m}^{2} \cdot \mathrm{min}^{0.5}\right)$, respectively, at 28 and 90 days, which correspond to a reduction of this coefficient by about $39 \%$ and $28 \%$, relative to the REF mortar.

When SWF and FBA were combined, the capillary coefficient achieved a value of about $2 \mathrm{~kg} /\left(\mathrm{m}^{2} \cdot \mathrm{min}^{0.5}\right)$, which is considered high for this coefficient, corresponding to twice the value of the SWP + FBA mortar. The addition of SWP to SWF+FBA, which results in the SWF+SWP+FBA mortar, was responsible for a decrease in the capillary coefficient. The value obtained was 1.25 and $1.33 \mathrm{~kg} /\left(\mathrm{m}^{2} \cdot \mathrm{min}^{0.5}\right)$, at 28 days and 365 days, respectively. These values were lower than the ones presented by the REF mortar, by about $14 \%$. Thus, the SWF+SWP+FBA mortar absorbed less water in the first minutes of the test, meaning that this mortar absorbs water slower than REF's. In a real application, the mortar would take more time to absorb water than REF's.

Concerning total absorption, only the SWP+FBA mortar showed an absorption lower than REF's. SWF+FBA and the SWF+SWP+FBA presented higher increments of water. The SWF+SWP+FBA mortar presented an absorption higher than the one presented by the REF mortar, by about $13 \%$. The mortar took longer to absorb water but over time it absorbed a greater amount of water than REF's. The incorporation of SWP into the SWF+FBA mortar reduced the volume of water absorbed, but not enough to be smaller than REF's. Thus, the negative effects of SWF and FBA were predominant over the benefits of the SWP waste.

The mechanism of the SWF+SWP+FBA mortar's absorption is explained by its porosity. This mortar has a larger volume of pores within the capillary range, and that is why it absorbs a greater amount of water. However, the diameter of these pores is probably smaller than REF's, which explains the slower absorption of water. In order to evaluate the porosity of the mortars, the open porosity test was performed (Table 2). The open porosity test showed that SWF+SWP+FBA presented a porosity higher than REF's from 28 days until 365 days. The open porosity of SWF+SWP+FBA was about $26 \%$ while that of the REF mortar was between $24 \%$ and $25 \%$, depending on age.

The porosity of the mortars influenced not only their water absorption behaviour but also their drying behaviour. Water drying was analysed over time from the loss of water curves.

In Figure 2, the drying curves of the mortars at 28 days and 365 days are presented. From the curves three different drying phases were identified, which correspond to the mechanism of water transport (liquid, vapour or mixed transport) until achieving the surface of the specimens and evaporating. 
Table 2. Water absorption and open porosity test results.

\begin{tabular}{|c|c|c|c|c|c|c|c|c|}
\hline \multirow[b]{2}{*}{ TEST } & \multirow{2}{*}{ Days } & \multicolumn{7}{|l|}{ MORTARS } \\
\hline & & REF & SWF & SWP & FBA & SWF+FBA & SWP+FBA & SWF+SWP+FBA \\
\hline \multirow{2}{*}{ Capillary coefficient $\left(\mathrm{kg} /\left(\mathrm{m}^{2} \cdot \mathrm{min}^{0.5}\right)\right)$} & 28 & $1.45 \pm 0.03$ & $1.58 \pm 0.10$ & $0.78 \pm 0.01$ & $1.50 \pm 0.10$ & $2.03 \pm 0.10$ & $0.89 \pm 0.12$ & $1.25 \pm 0.07$ \\
\hline & 365 & $1.55 \pm 0.07$ & - & - & $1.70 \pm 0.01$ & $1.90 \pm 0.09$ & $1.11 \pm 0.05$ & $1.33 \pm 0.05$ \\
\hline \multirow{2}{*}{ Total water absorption $\left(\mathrm{kg} / \mathrm{m}^{2}\right)$} & 28 & $17.31 \pm 0.13$ & $21.14 \pm 0.77$ & $24.07 \pm 0.44$ & $17.65 \pm 0.48$ & $23.94 \pm 0.52$ & $16.14 \pm 0.54$ & $19.57 \pm 0.23$ \\
\hline & 365 & $17.47 \pm 0.31$ & - & - & $18.00 \pm 0.28$ & $23.53 \pm 0.80$ & $16.79 \pm 0.36$ & $19.87 \pm 0.22$ \\
\hline \multirow{2}{*}{ Open porosity (\%) } & 28 & $24.3 \pm 0.3$ & $29.7 \pm 0.5$ & $19.3 \pm 0.3$ & $23.5 \pm 0.5$ & $30.6 \pm 0.2$ & $20.9 \pm 0.5$ & $25.7 \pm 0.2$ \\
\hline & 365 & $23.6 \pm 0.3$ & - & - & $24.0 \pm 0.2$ & $29.3 \pm 0.4$ & $21.2 \pm 0.3$ & $26.5 \pm 0.4$ \\
\hline \multirow{2}{*}{$\begin{array}{l}\text { Drying rate } \\
\text { First phase }\left(\mathrm{kg} /\left(\mathrm{m}^{2} \cdot \mathrm{h}\right)\right)\end{array}$} & 28 & 0.10 & 0.14 & 0.17 & 0.18 & 0.07 & 0.09 & 0.18 \\
\hline & 365 & 0.22 & - & - & 0.09 & 0.15 & 0.13 & 0.26 \\
\hline \multirow{2}{*}{$\begin{array}{l}\text { Drying rate } \\
\text { Second phase }\left(\mathrm{kg} /\left(\mathrm{m}^{2} \cdot \mathrm{h}^{0.5}\right)\right)\end{array}$} & 28 & 0.76 & 2.03 & 0.96 & 0.92 & 1.13 & 0.73 & 0.54 \\
\hline & 365 & 1.42 & - & - & 1.33 & 1.75 & 1.11 & 1.25 \\
\hline \multirow{2}{*}{$\begin{array}{l}\text { Drying rate } \\
\text { Third phase }\left(\mathrm{kg} /\left(\mathrm{m}^{2} \cdot \mathrm{h}^{0.5}\right)\right)\end{array}$} & 28 & 0.24 & 0.26 & 0.13 & 0.32 & 0.22 & 0.17 & 0.16 \\
\hline & 365 & 0.19 & - & - & 0.21 & 0.22 & 0.18 & 0.21 \\
\hline \multirow{2}{*}{ Drying index } & 28 & 0.25 & 0.28 & 0.34 & 0.16 & 0.22 & 0.33 & 0.53 \\
\hline & 365 & 0.09 & - & - & 0.09 & 0.08 & 0.10 & 0.23 \\
\hline Reference & & - & [5] & [6] & [14] & - & - & - \\
\hline
\end{tabular}



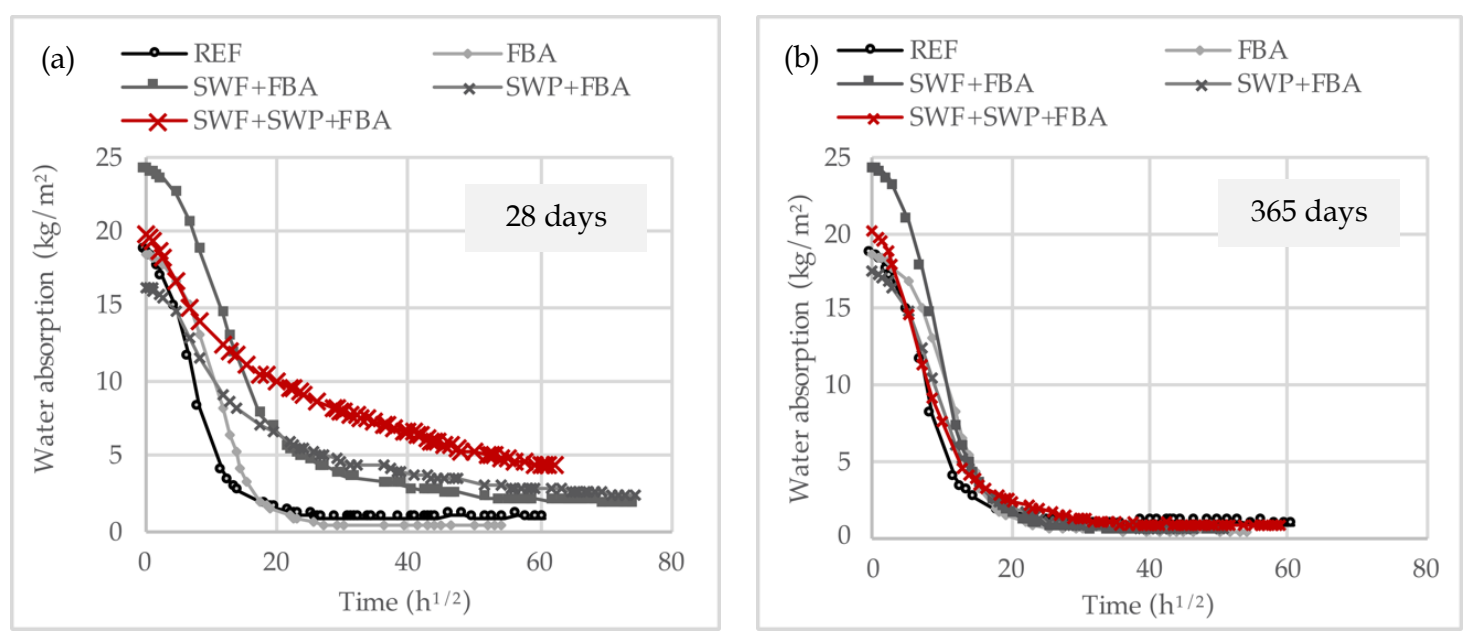

Figure 2. Drying curves (loss of water per square root of time) at 28 days (a) and 365 days (b).

Figure 2 shows that the drying behaviour differed from 28 to 365 days. At early ages, a major difference between the mortars was noticed. At 365 days, the behaviour was similar for all the mortars.

At 28 days, the ternary mix mortar (SWF+SWP+FBA) present the worst drying behaviour. It was noticed that the mortar presented a higher drying rate in the first phase (liquid transport) and lower drying rates in the remaining phases (mixed transport-predominantly liquid or predominantly in vapour). From the drying index, which gives a general idea about the drying behaviour, the mortar had more difficulty in drying than the REF mortar, at both ages analysed (Table 2). The incorporation of SWP waste in the SWF+FBA mortar was responsible for a reduction of the pores' diameter, which resulted in slower water absorption, which is favourable in rendering mortars. However, whenever this mortar absorbs a considerable volume of water it has more difficulty in releasing that same amount than a render mortar without wastes (REF mortar). Nevertheless, from 28 days to 365 days, an improvement of the drying behaviour was noticed.

SWF+FBA, of the combined wastes' mortars, was the most absorbent one, but it was also the one that dried more easily. SWP+FBA and SWF+SWP+FBA presented lower capillary coefficients, absorbing water slower than REF, but at 28 days they had more difficulty in drying. However, at 365 days, this negative effect was eliminated, and the mortars presented a similar behaviour to the REF mortar. This change of behaviour can be due to a modification of the pore structure of the mortars over time. The cementitious matrix of the mortars presents shrinkage over time, which is responsible for an increment of the volume of the large pores of the mortars [41] and consequently increments water absorption and improves water drying.

\subsection{Mechanical Behaviour}

The mechanical behaviour of the mortars was analysed through their deformability and mechanical strengths.

The deformability of the mortars was evaluated through the modulus of elasticity test and the results are presented in Table 3. 
Table 3. Modulus of elasticity, flexural strength and compressive strength test results.

\begin{tabular}{|c|c|c|c|c|c|c|c|c|}
\hline \multirow{2}{*}{ TEST } & \multirow{2}{*}{ Days } & \multicolumn{7}{|l|}{ MORTARS } \\
\hline & & REF & SWF & SWP & FBA & SWF+FBA & SWP+FBA & SWF+SWP+FBA \\
\hline \multirow{4}{*}{ Modulus of elasticity (GPa) } & 28 & $10.2 \pm 0.7$ & $8.2 \pm 0.4$ & $18.6 \pm 0.3$ & $8.1 \pm 0.5$ & $5.8 \pm 0.4$ & $14.4 \pm 0.2$ & $12.4 \pm 0.4$ \\
\hline & 90 & $8.0 \pm 0.3$ & $8.1 \pm 0.2$ & $17.3 \pm 0.3$ & $7.4 \pm 0.4$ & $4.9 \pm 0.7$ & $12.6 \pm 0.2$ & $10.0 \pm 0.4$ \\
\hline & 180 & $8.7 \pm 0.9$ & - & - & $5.7 \pm 0.5$ & $4.6 \pm 0.1$ & $12.1 \pm 0.6$ & $8.9 \pm 0.3$ \\
\hline & 365 & $9.7 \pm 0.3$ & - & - & $6.6 \pm 0.2$ & $5.2 \pm 0.4$ & $11.8 \pm 0.4$ & $9.4 \pm 0.2$ \\
\hline \multirow{4}{*}{ Flexural strength (MPa) } & 28 & $2.10 \pm 0.32$ & $1.41 \pm 0.10$ & $4.39 \pm 0.24$ & $1.37 \pm 0.14$ & $1.10 \pm 0.11$ & $2.62 \pm 0.05$ & $2.71 \pm 0.17$ \\
\hline & 90 & $1.54 \pm 0.19$ & $1.83 \pm 0.19$ & $2.27 \pm 0.27$ & $1.49 \pm 0.19$ & $1.59 \pm 0.25$ & $2.65 \pm 0.37$ & $3.01 \pm 0.28$ \\
\hline & 180 & $1.79 \pm 0.16$ & - & - & $1.35 \pm 0.16$ & $0.96 \pm 0.15$ & $2.72 \pm 0.34$ & $3.00 \pm 0.68$ \\
\hline & 365 & $1.94 \pm 0.17$ & - & - & $1.38 \pm 0.14$ & $1.27 \pm 0.13$ & $2.83 \pm 0.29$ & $2.85 \pm 0.11$ \\
\hline \multirow{5}{*}{ Compressive strength (MPa) } & 28 & $5.19 \pm 0.45$ & $5.85 \pm 0.49$ & $14.92 \pm 0.29$ & $4.30 \pm 0.52$ & $3.37 \pm 0.19$ & $9.42 \pm 0.58$ & $9.21 \pm 0.33$ \\
\hline & 90 & $3.58 \pm 0.22$ & $3.90 \pm 0.43$ & $9.55 \pm 0.49$ & $3.82 \pm 0.38$ & $3.53 \pm 0.39$ & $10.38 \pm 0.71$ & $9.47 \pm 0.57$ \\
\hline & 120 & - & $3.47 \pm 0.19$ & $7.77 \pm 0.29$ & - & - & - & - \\
\hline & 180 & $3.96 \pm 0.42$ & - & - & $2.92 \pm 0.41$ & $3.05 \pm 0.19$ & $9.69 \pm 0.95$ & $7.92 \pm 0.42$ \\
\hline & 365 & $5.86 \pm 0.58$ & - & - & $2.87 \pm 0.51$ & $2.86 \pm 0.07$ & $8.21 \pm 0.37$ & $8.53 \pm 0.24$ \\
\hline Reference & & - & [5] & [6] & [14] & - & - & - \\
\hline
\end{tabular}


It was noticed that the SWF+FBA presented a low modulus of elasticity (around $5 \mathrm{GPa}$ ), which was expected, and is in accordance with the results of water absorption and open porosity tests. Contrarily, the SWP+FBA mortar presented a modulus of elasticity between 12 and $14 \mathrm{GPa}$, which is an intermediate value between the SWP (around 17-19 GPa) and the FBA mortars (around 6-8 GPa). FBA was able to reduce the modulus of elasticity of the SWP mortar (in SWP+BBA), but it is still too high when compared with the one of REF (around 8-10 GPa). Concerning the SWF+SWP+FBA mortar, its modulus of elasticity was higher than REF's until 90 days. For later ages, it decreased and became similar to or less than REF's. The decrease of modulus of elasticity over time could have indicated internal micro-cracking of the specimens. This micro-cracking was also noticed in the SWP mortar [6].

The flexural and compressive strength tests results are presented in Table 3 and Figures 3 and 4 . They are in accordance with those of the modulus of elasticity. SWF+FBA presented strengths lower than REF's. SWP+FBA, on the contrary, was noticed to be stronger than the REF mortar, as well as $\mathrm{SWF}+\mathrm{SWP}+\mathrm{FBA}$. The ternary mix mortar $(\mathrm{SWF}+\mathrm{SWP}+\mathrm{FBA})$ presented a flexural strength between 2.7 and $3.0 \mathrm{MPa}$, between 28 and 365 days. The REF mortar presented, on the other hand, flexural strength between 1.5 and $2.1 \mathrm{MPa}$, at the same ages. In fact, the SWF+SWP+FBA mortar presented a large increment of flexural strength when compared to the REF mortar. This large increment was mainly due to the SWP waste [6]. Nevertheless, comparing the SWP+FBA and SWF+SWP+FBA mortars, it was concluded that when SWF was added in the ternary mix of wastes the strengths improved when compared with SWP+FBA. So, the SWF waste was also responsible for the increment of strength. It is concluded that a good symbiosis between the wastes was achieved, improving the mechanical strength of the mortar.

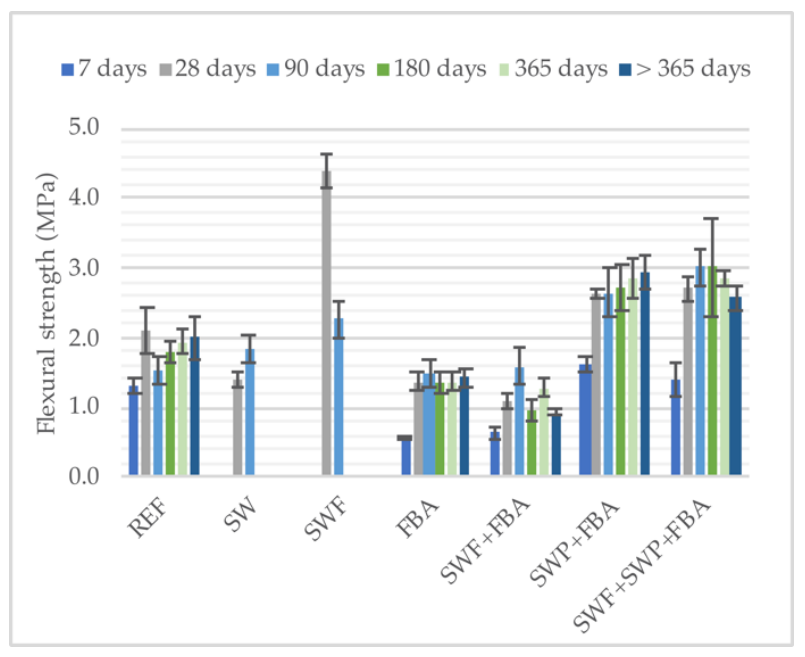

Figure 3. Flexural strength test results.

In the compressive strength test (results presented in Table 3 and Figure 4), it was found that the SWF+SWP+FBA mortar presented a strength that varied between 7.9 and $9.2 \mathrm{MPa}$, at 28 days. These values are considerably higher than the ones of the REF mortar (between 3.6 and 5.9 MPa). In this test, it is also clear that the waste that was responsible for this increment of strength was SWP. Contrary to flexural strength, the addition of SWF to the SWP+FBA mortar was not favourable for compressive strength, since it presented slightly higher values for SWF+FBA than the SWF+SWP+FBA mortar in most curing ages. The angular particles of SW were more favourable in flexural strength than in compressive strength. In the compressive strength test results, a slight decrease over time was noticed. This had already been noticed in the SWP mortar and micro-cracking had been identified as the reason. Susceptibility to micro-cracking seems to also affect the SWF+SWP+FBA mortar. Micro-cracking is also responsible for the results obtained in the modulus of elasticity test, water absorption and water drying: a lower modulus of elasticity, a higher absorption and a faster drying behaviour over time were noticed. However, the reduction of strength was slight and is not comparable with the one 
presented by the SWP mortar, meaning that the SWF and the FBA wastes decreased this susceptibility; although they were not able to completely eliminate it, they were responsible for a minimization of this disadvantage of the mortar.

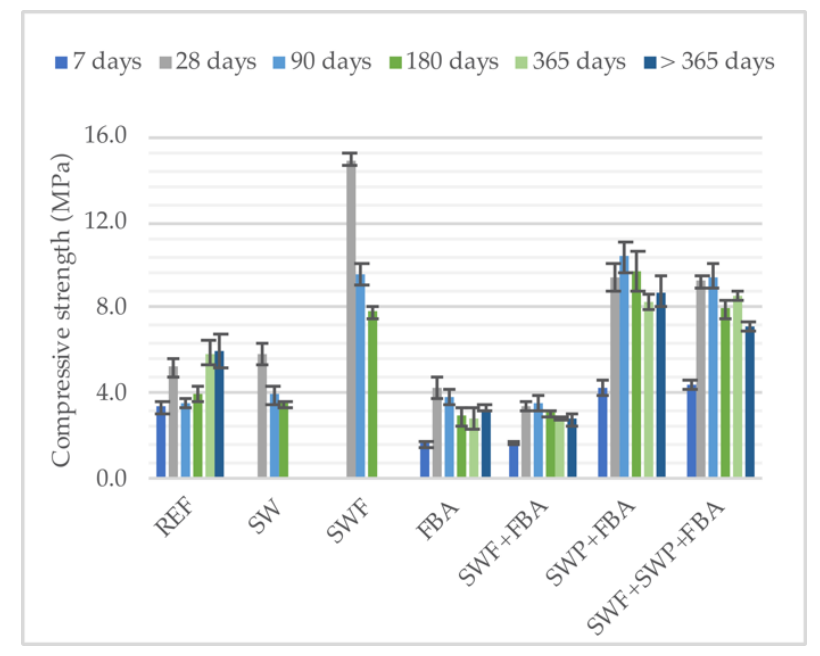

Figure 4. Compressive strength test results.

\section{Conclusions}

The aim of this research was to fine-tune three mortars that have been already studied and contained wastes in their formulation, replacing cement or sand. The first one contained forest biomass ashes (replacing cement at $15 \%$ by volume), the second one contained powder of sanitary ware waste (replacing sand at $20 \%$ by volume) and the third mortar contained sanitary ware waste fine aggregates (replacing sand at $100 \%$ ). The modified mortars improved some properties of the render mortars, when compared with a reference mortar, but they worsened others. In order to improve these modified mortars, the wastes were combined two-by-two and then the three of them were combined.

Several tests were performed in order to evaluate the fresh-state, water and mechanical behaviour of the mortars in order to evaluate their technical performance. The main conclusions obtained from this research were:

- The incorporation of some wastes in rendering mortars is viable and is a solution to reduce landfilling;

- The industrial wastes studied in this research (FBA, SWP and SWF) can reduce the amount of natural resources extracted used in mortars (as sand and cement), replacing them and producing technically viable mortars;

- It is possible to achieve mortars simultaneously with $83 \%$ of wastes and better technical performance than a conventional mortar;

- It is possible to combine wastes and take advantage of the best features of each one, maximising their advantages and minimising their limitations;

- The mortars that presented better technical performance were SWP+FBA and SWF+SWP+FBA, with respectively $19 \%$ and $83 \%$ of recycled volume;

- The SWP+FBA and SWF+SWP+FBA mortars presented better fresh-state behaviour, better water behaviour, characterized by lower water absorption, and higher mechanical strengths than the ones presented by the REF mortar.

This research contributed to the scientific knowledge on rendering mortars and the incorporation of wastes in hydraulic materials. The incorporation of the wastes in mortars reduces the environmental impacts, not only of the new materials, but also the ones that the wastes would be responsible for if they were sent to landfill, and simultaneously improves the technical performance of the mortars. 
Author Contributions: C.B.F. performed the experiments in the laboratories of Building Coatings and Thermal Insulation Unit, of Portuguese National Laboratory for Civil Engineering; C.B.F. and R.V. analysed the fresh, water and mechanical tests and discussed the obtained results; J.d.B. and R.V. were responsible for the supervision of the research. Writing - original draft preparation was performed by C.B.F. and writing-review and editing by J.d.B. and R.V. All authors have read and agreed to the published version of the manuscript.

Funding: This research was funded by Portuguese Foundation for Science and Technology (PD/BD/113639/2015).

Acknowledgments: The authors would like to acknowledge the REuSE project from National Laboratory for Civil Engineering of Portugal (LNEC) and the research unit CERIS from Instituto Superior Técnico (IST).

Conflicts of Interest: The authors declare no conflict of interest.

\section{References}

1. Eurostat. Waste Statistics in Europe, Statistics Explained. Available online: https://ec.europa.eu/eurostat/ statistics-explained/index.php/Waste_statistics. (accessed on 20 December 2019).

2. European Cement Research Academy (ECRA). Environmental Product Declaration Report. Portland-Composite Cement (CEM II) Produced in Europe 2015. Available online: https://cembureau. eu/media/1255/6117_cembureau_epd_cemii_2015-02-01.pdf (accessed on 20 December 2019).

3. European Commission, Being Wise with Waste: The EU's Approach to Waste Management; Publications Office of the European Union: Luxembourg, 2010; p. 20.

4. European Parliament and of the Council and Official Journal of the European Union. European Directive 2008/98/EC: On Waste and Repealing Certain Directives (Text with EEA Relevance). 2008. Available online: https://eur-lex.europa.eu/legal-content/EN/TXT/PDF/?uri=CELEX:32008L0098\&from=EN (accessed on 20 December 2019).

5. Lucas, J.; de Brito, J.; Veiga, R.; Farinha, C.B. The effect of using sanitary ware as aggregates on rendering mortars' performance. Mater. Des. 2016, 91, 155-164. [CrossRef]

6. Farinha, C.B.; de Brito, J.; Veiga, R. Incorporation of fine sanitary ware aggregates in coating mortars. Constr. Build. Mater. 2015, 83, 194-206. [CrossRef]

7. Pliya, P.; Cree, D. Limestone derived eggshell powder as a replacement in Portland cement mortar. Constr. Build. Mater. 2015, 95, 1-9. [CrossRef]

8. Araya-letelier, G.; Antico, F.C.; Carrasco, M.; Rojas, P.; García-herrera, C.M. Effectiveness of new natural fibers on damage-mechanical performance of mortar. Constr. Build. Mater. 2017, 152, 672-682. [CrossRef]

9. Sathiparan, N.; Nishanthana, M.; Pavithra, B.H.M. Performance of coconut coir reinforced hydraulic cement mortar for surface plastering application. Constr. Build. Mater. 2017, 142, 23-30. [CrossRef]

10. Fujiyama, R.; Darwish, F.; Pereira, M. Mechanical characterization of sisal fiber reinforced cement mortar. In Proceedings of the 13th International Conference on Fracture, Beijing, China, 16-21 June 2013.

11. Spadea, S.; Farina, I.; Carrafiello, A.; Fraternali, F. Recycled nylon fibers as cement mortar reinforcement. Constr. Build. Mater. 2015, 80, 200-209. [CrossRef]

12. Marzouk, O.Y.; Dheilly, R.M.; Queneudec, M. Valorization of post-consumer waste plastic in cementitious concrete composites. Waste Manag. 2007, 27, 310-318. [CrossRef]

13. Corinaldesi, V.; Nardinocchi, A.; Donnini, J. Reuse of recycled glass in mortar manufacturing. European J. Environ. Civ. Eng. 2016, 20, s140-s151. [CrossRef]

14. Farinha, C.B.; de Brito, J.; Veiga, R. Influence of forest biomass bottom ashes on the fresh, water and mechanical behaviour of cement-based mortars. Resour. Conserv. Recycl. 2019, 149, 750-759. [CrossRef]

15. Farinha, C.B.; de Brito, J.; Veiga, R. Assessment of glass fibre reinforced polymer waste reuse as filler in mortars. J. Clean. Prod. 2019, 210, 1579-1594. [CrossRef]

16. Silva, A.; de Brito, J.; Veiga, R. Incorporation of fine plastic aggregates in rendering mortars. Constr. Build. Mater. 2014, 71, 226-236. [CrossRef]

17. Jesus, S.; Maia, C.; Farinha, C.B.; de Brito, J.; Veiga, R. Rendering mortars with incorporation of very fine aggregates from construction and demolition waste. Constr. Build. Mater. 2019, 229, 116844. [CrossRef]

18. Pedro, D.; de Brito, J.; Veiga, R. Mortars made with fine granulate from shredded tires. J. Mater. Civ. Eng. 2013, 25, 519-529. [CrossRef] 
19. Oliveira, R.; de Brito, J.; Veiga, R. Incorporation of fine glass aggregates in renderings. Constr. Build. Mater. 2013, 44, 329-341. [CrossRef]

20. Penacho, P.; de Brito, J.; Veiga, R. Physico-mechanical and performance characterization of mortars incorporating fine glass waste aggregate. Cem. Concr. Compos. 2014, 50, 47-59. [CrossRef]

21. Silva, J.; de Brito, J.; Veiga, R. Incorporation of fine ceramics in mortars. Constr. Build. Mater. 2009, 23, 556-564. [CrossRef]

22. Braga, M.; de Brito, J.; Veiga, R. Reduction of the cement content in mortars made with fine concrete aggregates. Mater. Struct. 2014, 47, 171-182. [CrossRef]

23. Neno, C.; de Brito, J.; Veiga, R. Using fine recycled concrete aggregate for mortar production. Mater. Res. 2014, 17, 168-177. [CrossRef]

24. Farinha, C.B.; de Brito, J.; Veiga, R.; Lucas, J. Reduction of cement content in renderings with fine sanitary ware aggregates. Mater. Struct. 2016, 49, 1605-1618. [CrossRef]

25. Lucas, J. Performance of Mortars with Incorporation of Fine Aggregates of Sanitary Ware Waste. Aggregates Recycling. Master's Thesis, Instituto Superior Técnico, Lisbon, Portugal, University of Lisbon, Lisbon, Portugal, 2015.

26. Braga, M.; de Brito, J.; Veiga, R. Incorporation of fine concrete aggregates in mortars. Constr. Build. Mater. 2012, 36, 960-968. [CrossRef]

27. Farinha, C.B.; Silvestre, J.; de Brito, J.; Veiga, R. Life cycle assessment of mortars with incorporation of industrial wastes. Fibers 2019, 7, 59. [CrossRef]

28. Tosti, L.; van Zomeren, A.; Pels, J.R.; Dijkstra, J.J.; Comans, R.N.J. Assessment of biomass ash applications in soil and cement mortars. Chemosphere 2019, 223, 425-437. [CrossRef] [PubMed]

29. Rajamma, R.; Senff, L.; Ribeiro, M.J.; Labrincha, J.A.; Ball, R.J.; Allen, G.C.; Ferreira, V.M. Biomass fly ash effect on fresh and hardened state properties of cement based materials. Compos. Part B Eng. 2015, 77, 1-9. [CrossRef]

30. Tosti, L.; van Zomeren, A.; Pels, J.R.; Comans, R.N.J. Technical and environmental performance of lower carbon footprint cement mortars containing biomass fly ash as a secondary cementitious material. Resour. Conserv. Recycl. Recycl. 2018, 134, 25-33. [CrossRef]

31. Jackiewicz-Rek, W.; Załęgowski, K.; Garbacz, A.; Bissonnette, B. Properties of cement mortars modified with ceramic waste fillers. Procedia Eng 2015, 108, 681-687. [CrossRef]

32. Veiga, R. Behaviour of Renderings Mortars: Contribution for the Research in Cracking Resistance. Ph.D. Thesis, Civil Engineering, Faculty of Engineering of the University of Porto, Porto, Portugal, 1998. (In Portuguese)

33. Higashiyama, H.; Yagishita, F.; Sano, M.; Takahashi, O. Compressive strength and resistance to chloride penetration of mortars using ceramic waste as fine aggregate. Constr. Build. Mater. 2012, 26, 96-101. [CrossRef]

34. Torkittikul, P.; Chaipanich, A. Utilization of ceramic waste as fine aggregate within Portland cement and fly ash concretes. Cem. Concr. Compos. 2010, 32, 440-449. [CrossRef]

35. EN 1015-3: Methods of Test for Mortar for Masonry_Part 3: Determination of Consistence of Fresh Mortar (by Flow Table); European Committee for Standarization (CEN): Brussels, Belgium, 1999.

36. Cahier 2669-4, Certification CSTB Des Enduits Monocouches D'imperméabilisation. Modalités D'essais, Centre Scientifique et Technique du Bâtiment, Paris, France, 1993.

37. EN 1015-18: Methods of Test for Mortar for Masonry_Part 18: Determination of Water Absorption Coefficient Due to Capillary Action of Hardened Mortar; European Committee for Standarization (CEN): Brussels, Belgium, 2002.

38. EN 16322: Conservation of Cultural Heritage_-Test Methods_Determination of Drying Properties; European Committee for Standarization (CEN): Brussels, Belgium, 2013.

39. EN 1015-11: Methods of Test for Mortar for Masonry_Part 11: Determination of Flexural and Compressive Strength of Hardened Mortar; European Committee for Standarization (CEN): Brussels, Belgium, 1999.

40. EN 14146: Natural Stone tests Methods: Determination of the Dynamic modulus of Elasticity (by Measuring the Fundamental Resonance Frequency); European Committee for Standarization (CEN): Brussels, Belgium, 2004. 
41. Santos, R. The Influence of Natural Aggregates on the Performance of Replacement Mortars for Ancient Buildings: The Effects of Mineralogy, Grading and Shape. Ph.D. Thesis, Instituto Superior Técnico, Lisbon, Portugal, Civil Engineering, University of Lisbon, Lisbon, Portugal, 2019. 